\title{
A ESTRATÉGIA INSTITUCIONAL DO SUPREMO TRIBUNAL FEDERAL NO PROCESSO LEGISLATIVO
}

\section{THE INSTITUTIONAL STRATEGY OF BRAZILIAN SUPREME COURT ON THE LEGISLATIVE PROCESS}

\author{
${ }^{1}$ Fernando Bentes
}

\section{RESUMO}

A Constituição Federal brasileira fixou um desenho estrutural de competências que permite uma ampla atuação do Supremo Tribunal Federal sobre a vida social e os ramos de governo. No entanto, a análise da teoria institucionalista estratégica sobre os julgados relativos ao processo legislativo federal demonstra que não há um panorama assimétrico entre os departamentos estatais. Na verdade, o jogo entre poderes pode criar cenários conjunturais que libertam decisões baseadas na preferência individual dos julgadores ou que restringem a autonomia da Corte quando críticas ou retaliações externas ameaçam sua permanência e autoridade.

Palavras-chave: Supremo Tribunal Federal; Congresso Nacional; separação de poderes; processo legislativo; institucionalismo.

\begin{abstract}
The Brazilian Federal Constitution established a framework of laws that allow for the Supreme Court to act over the social life and branches of the government. Nevertheless, the analysis of the federal legislative process by the strategic institutional approach demonstrates that the panorama among state departments is not asymmetric. In fact, the separation of powers game can create groups of scenarios that generate decisions based on the preference of individual judges, or that restrict the autonomy of the Court when criticism or external retaliations threaten its authority.
\end{abstract}

Keywords: Brazilian Supreme Court; Brazilian National Congress; separation of powers; legislative process; institutionalism.

\footnotetext{
${ }^{1}$ Doutor em Direito Constitucional e Teoria do Estado pela Pontifícia Universidade Católica do Rio de Janeiro (PUC-Rio), Rio de Janeiro, Brasil. Professor do Mestrado em Direito pela Universidade Presidente Antônio Carlos (UNIPAC), Barbacena, Minas Gerais, Brasil. Emial: fernandobentes@ufrrj.br
} 


\section{INTRODUÇÃO}

O objetivo deste trabalho é revelar as estratégias decisórias empregadas pelo Supremo Tribunal Federal ao julgar ações sobre o processo legislativo federal.

A teoria institucionalista será utilizada como um meio de analisar a jurisprudência da Corte e esclarecer algumas nuances de seu comportamento, contribuindo para que outros fatores decisórios sejam revelados além dos fundamentos puramente jurídicos.

Com base em contribuições teóricas predominantemente norte-americanas, este enfoque institucionalista pode desvendar as preocupações judiciais que afloram neste gênero delicado de processos, que lidam com relações entre ramos do governo. Como o processo legislativo se desenvolve numa dinâmica eminentemente congressual, qualquer atuação do Supremo pode significar uma intromissão indevida, ilegítima ou que viola a separação de poderes.

\section{O INSTITUCIONALISMO ESTRATÉGICO}

O institucionalismo estratégico considera os arranjos institucionais como um limite de comportamento de seus atores, compreendidos como agentes utilitários e calculadores, que almejam maximizar seus ganhos e minimizar suas perdas. As instituições só permanecem se atingem um equilíbrio de interesse entre seus agentes, ou seja, se tornam possíveis os ganhos resultantes de trocas internas (FEREJOHN; KRAMER, 2002, p. 994; WEINGAST; MARSHAL, 1988, PP. 132-163).

Dentro do debate institucionalista norte-americano, esta perspectiva estratégica se opõe a outra corrente de estudos baseada na atitude. Na análise da Suprema Corte, esta abordagem delineia a narrativa comportamental de cada "justice" como um meio de antecipação fidedigna de sua conduta decisória. Embora aceite o pressuposto realista de juízes como maximizadores de ideologias e valores, o atitudinalismo assume que encontram circunstâncias plenas de concretização de seus interesses sinceros e individuais. Logo, não precisam interagir em nenhum jogo estratégico para afirmar suas preferências (SEGAL; SPAETH, 2002, p. 86; SEGAL, 1997, p. 28; MALTZMAN; SPRIGGS; WHALBECK, 1999, pp. 43-46). 
A viabilidade deste modelo depende da possibilidade de afirmação de preferências pessoais sem o constrangimento de fatores endógenos - outros colegas julgadores - e exógenos - pressões de outras instituições. Portanto, o atitudinalismo se esforça em defender todas as circunstâncias criadoras de uma atmosfera de liberdade decisória dos juízes constitucionais, como a impossibilidade de recurso de suas deliberações; a indicação de juristas com carreira consolidada e sem ambições por cargos futuros, pelos quais devessem fazer concessões a grupos de interesse; o processo de indicação presidencial com sabatina senatorial independente de circunstâncias eleitorais (BAUM, 1999, p. 205-211; SEGAL; SPAETH, 2002, p. 86; MALTZMAN; SPRIGGS; WHALBECK, 1999, p. 43-46).

Esta conjuntura de liberdade decisória também se verifica no Brasil. Reproduzindo o mesmo critério de seleção dos ministros do Supremo Tribunal Federal, com indicação presidencial e sabatina senatorial ${ }^{2}$, a nomeação destes candidatos em seu apogeu profissional diminui a possibilidade de que abdiquem de seus princípios e valores em nome de projetos políticos de atores exógenos. Além destas circunstâncias existem outros incentivos estruturais que contribuem para esta atmosfera de liberdade decisória, como a ausência de mandato fixo, com aposentadoria obrigatória em idade avançada, aos setenta e cinco anos, e garantias judiciais de vedam a redução salarial e a remoção compulsória do cargo (BRINKS, 2010, pp. 236-248) ${ }^{3}$.

Além de todas estas circunstâncias que favorecem a autonomia decisória, o institucionalismo atitudinal questiona seriamente que os juízes constitucionais possam ter informações completas e confiáveis sobre a vontade parlamentar. Ora, diante desta dificuldade, não poderiam incorporar em sua decisão as possíveis retaliações legislativas. (DAVIDSON, 1988, pp. 96-102 e 110; SEGAL, 1999, p. 244; Idem, 1997, pp. 31 e 35).

Embora o modelo atitudinal não seja utilizado como ferramenta teórica deste trabalho, seu confronto com a perspectiva estratégica ajuda a esclarecer algumas análises sobre a jurisprudência do Supremo Tribunal Federal. Antes desta etapa, porém, é necessário distinguir dois enfoques estratégicos diferentes sobre o comportamento decisório: o jogo colegial e o sistema político.

\footnotetext{
${ }^{2}$ Art. 101, parágrafo único, $\mathrm{CF}$.

${ }^{3}$ Art. $40, \S 1^{\circ}$, inciso II, CF.
} 


\subsection{O JOGO COLEGIAL}

O jogo colegial é um enfoque estratégico que aborda todos os aspectos endógenos envolvidos na circunstância de uma decisão que é tomada coletivamente, ou seja, as normas de conduta, o regimento, a agenda da corte, a opinião dos outros juízes, o processo de convencimento de seus pares e a formação do posicionamento final. Parte-se do pressuposto de que um sujeito conta pouco se não houver outros decidindo igualmente (MALTZMAN; SPRIGGS; WHALBECK, 1999, pp. 46-48) ${ }^{4}$.

Vários estudos mostram eventos de coalizão na Corte, o que revela a necessidade de integração utilitária entre juízes, relatores e presidentes sob pena de a instituição se transformar numa arena descoordenada. Esta interação demonstra que os julgadores mudam suas preferências e dão votos diferentes de sua convicção pessoal. $\mathrm{O}$ ator não decide de maneira livre e isolada, porque isto pode significar uma carreira de derrotas sucessivas e, consequentemente, de nenhuma vitória de suas convicções. (MALTZMAN; SPRIGGS; WHALBECK, 1999, pp. 51-57). A própria aderência à tese decisória não depende apenas de um alinhamento ideológico, mas no fato de seu autor ter cooperado nos casos de interesse de um juiz ou se estabelecer um compromisso de fazê-lo, no futuro (MALTZMAN; SPRIGGS; WHALBECK, 1999, pp. 51-57).

Outro dado apontado pelas pesquisas norte-americanas é o fundamental papel exercido pela relatoria na Suprema Corte (MALTZMAN; SPRIGGS; WHALBECK, 1999, pp. 51-57). De modo semelhante, a relatoria dos processos de competência do Supremo Tribunal Federal também apresenta um grande potencial estratégico. Dentre suas atribuições, destacam-se a narração dos acontecimentos e peças dos autos, a permissão de intervenções externas, como o amicus curiae, a concessão de liminares, o voto inicial e a redação da ementa e do acórdão. Tendo em vista suas atribuições destacadas, percebe-se um engajamento especial dos ministros em defender suas posições nos casos que relatam, até porque, todas as manifestações colegiais tendem a satelizar a aderência ou rejeição à sua tese condutora, que assume uma função de estruturar as reflexões jurídicas, condicionar o debate e influenciar na repercussão do caso e na própria decisão final.

Na Suprema Corte dos Estados Unidos, há uma dificuldade maior de se mapear todo esse debate capitaneado pelo relator, uma vez que delibera em caráter secreto.

\footnotetext{
${ }^{4} \mathrm{Na}$ Suprema Corte, este fato é conhecido como o "Rule of Four", a regra dos quatro: uma preferência só pode ser afirmada se, pelo menos, outros quatro juízes decidirem igualmente, tendo em vista que o colegiado é composto por nove membros totais.
} 
Diferentemente, o Supremo decide em sessão pública, o que transforma as diferenças entre os ministros num debate retórico aberto. A pesquisa jurisprudencial constatou que esta publicidade cria um verdadeiro palco que os atores decisórios individuais exploram estrategicamente para constranger seus pares a seguirem um entendimento. Os ministros usam a possibilidade de crítica da opinião pública como um mecanismo de coação interna.

Dentre estes expedientes estratégicos utilizados pelos ministros do Supremo Tribunal Federal, a pesquisa jurisprudencial evidenciou o uso de declarações apelativas e o recurso a conceitos abstratos cujo significado foi intensamente disputado pelos julgadores, como as acepções sobre Constituição, separação de poderes, a maioria e a minoria, democracia, as questões políticas, regimentais ou interna corporis, o papel e as competências do Judiciário, do próprio Supremo Tribunal Federal e do Legislativo. Com um sentido extremamente aberto, estes termos servem para legitimar todo tipo de interpretação, além de rechaçar ou acuar alguns posicionamentos.

Além de favorecer pesquisas colegiais, este modelo aberto de julgamento também facilita uma abordagem estratégica voltada um cenário maior de instituições e influências, tema do próximo item.

\subsection{O SISTEMA POLÍTICO}

Neste enfoque, a ação do juiz singular é situada na perspectiva da corte, que atua como um ator estratégico uno e mantém relações com várias outras instituições. Suas decisões são o resultado da interação política com outros grupos de poder, como o legislativo, o executivo, burocracias especializadas, a mídia, corporações econômicas, sindicatos e associações religiosas, num processo de retroalimentação aberto a informações e estímulos exógenos que, por sua vez, cobram certos posicionamentos. Nesta dinâmica, os juízes constitucionais conseguem apurar sua sensibilidade e responsividade no horizonte de aceitação ou rejeição de várias entidades (CLAYTON; GILLMAN, 1999, p. 35).

De modo destacado entre todos os grupos de interesse, a imprensa se apresenta como porta-voz da opinião pública e reivindica que as decisões judiciais se direcionem num determinado sentido, o que pode trazer uma grande influência sobre o balanço decisório (BYBBE, 1999, p. 231-232). Inúmeros julgados identificaram esta forte preocupação do Supremo Tribunal Federal com a repercussão midiática de suas decisões. Além de diversas 
referências ao noticiário da imprensa, em vários processos, os ministros reservaram parte de seu voto para respondê-la direta e expressamente.

Além da mídia, somente as manifestações de parlamentares e autoridades do Congresso Nacional serviram como base de debate, crítica ou reforço de teses discutidas pelo colegiado. $\mathrm{O}$ estudo de todas estas pressões exógenas demonstra que as cortes constitucionais não estão isoladas, mas interagem com diversos atores que servem como fontes informacionais e exigem determinados comportamentos. Se não buscar uma compatibilização das preferências endógenas com estes grupos sociais e institucionais, um tribunal pode sofrer o risco de retaliações externas que abalam sua autoridade (EPSTEIN; KNIGHT, 1999, pp. 215-228).

Sob a mesma ótica de preservação institucional, ressalta-se o papel assumido pelo juiz-presidente da Suprema Corte, que tem um apreço maior do que seus pares com a harmonia interna, a repercussão na opinião pública e o alinhamento com o sistema político. (DAVIS, 1999, PP. 135-140) Esta preocupação da presidência também foi verificada em alguns julgados do Supremo Tribunal Federal, seja pelo esforço em responder especificamente às críticas da imprensa, seja para esclarecer detalhadamente suas próprias decisões.

Um enfoque teórico mais específico do sistema político recorta apenas as relações do judiciário com o legislativo, numa espécie de jogo estratégico entre poderes. Como premissa fundamental, esta perspectiva assume que a antecipação de ações legislativas força uma coletividade de julgadores a ajustar suas preferências para impedir comportamentos que minam sua autoridade institucional (SPILLER; RICHMAN; BERGARA, 2003, p. 267). Os atores decisórios não são condicionados apenas por suas preferências, mas também pelo grau de retaliação legislativa, o que une todo o colégio de julgadores numa preocupação compartilhada (HELMKE; STATON, 2010, p. 539). Um tribunal desgastado por ataques parlamentares não conseguirá atingir ou manter um grau de autonomia suficiente para que seus membros operem de maneira livre e autêntica (CLARK, 2009, p. 972; SEGAL; LINDQUIST, 2010, pp. 2-14).

Uma crítica legislativa exacerbada pode alertar que a corte constitucional não está ancorada na sociedade, o que acarretaria numa erosão de sua confiança pública (CLARK, 2009, pp. 972-978). Além de despertar a atenção sobre seu descolamento com anseios populares, ataques parlamentares agudos e diretos, reverberados pela mídia em escala nacional, podem lançar uma sombra de dúvida sobre sua legitimidade decisória. Discussões 
sobre projetos normativos que limitam o poder dos juízes constitucionais têm o mesmo potencial simbólico de corroer seu prestígio. Ainda que estas censuras possam remanescer como ameaças retóricas e não efetivas, o grau de periculosidade que representam para a integridade da corte não pode ser desprezado (CLARK, 2009, pp. 972-978; SEGAL; LINDQUIST, 2010, pp. 2-4).

Nestas conjunturas de constrangimento, há uma ação que representa uma possibilidade mais concreta de restrição da corte constitucional como ator político efetivo, a evasão legislativa, que se configura na perversão completa dos termos de uma decisão, numa atitude frontal de desafio a sua autoridade.

Porém, em algumas situações, este comportamento nem precisa ser flagrante. Por meio de provisões normativas abstratas, singelamente discordantes, imprecisas, ambíguas ou até pela omissão, os legisladores podem burlar completamente a deliberação das cortes de modo indireto, o que reduz a possibilidade de críticas por desrespeito à competência de outro poder (ESKRIDGE, 1991, p. 332; VANBERG, 2001, pp. 347 e 348) ${ }^{5}$.

A evasão legislativa é um padrão recorrente em um cenário de supremacia legislativa, quando os parlamentares são capazes de cumprir sua agenda política sem considerar as preferências das cortes constitucionais. O legislador não vê maiores problemas em aprovar qualquer ato ou escapar de sua invalidação judicial (ROGERS, 2001, p. 92; VANBERG, 2001, pp. 352-354).

Nesta conjuntura, os tribunais constitucionais possuem reticências em anular ações parlamentares, pois o risco de evasão legislativa é muito grande. Se ocorrer, a corte perderá duplamente: sua preferência será esvaziada e sua autoridade, abalada. Porém, se reconhecer a regularidade de uma lei, estará renunciando ao seu interesse, mas eliminará a hipótese de evasão e, consequentemente, de fraqueza institucional. Sendo assim, esta será a situação mais vantajosa e com risco menor, por isso, provavelmente irá validar a norma, assumindo um caráter submisso (VANBERG, 2001, p. 350).

Para não ofender os interesses legislativos e, ao mesmo tempo, reduzir críticas difusas por sua omissão, a corte pode se escorar mecanismos de sofisticação decisória, como a rejeição de sua competência para avaliar o caso ou limitando seu julgamento a aspectos tecnicistas ou formalistas (CLARK; FREIDMAN; HARVEY, 2006, pp. 534-537).

${ }^{5}$ Georg Vanberg cita um exemplo deste comportamento evasivo na Alemanha, quando a Corte Constitucional Federal invalidou uma norma que estabelecia o critério de pelo menos $2 \%$ de votos parlamentares para que um partido recebesse verbas do fundo partidário público. No entanto, o Legislativo aprovou outra lei em termos diferentes, que fugia da invalidação, mas permanecia discriminando agremiações políticas menores, ao estabelecer uma bonificação aos partidos que recebessem quantidades maiores de votos. 
Neste cenário de supremacia legislativa, a antecipação do comportamento parlamentar promove a renúncia de interesses individuais e a valorização de comportamentos estratégicos coletivos que resguardam a corte e criam a antessala de um cenário benfazejo. A proteção e o fortalecimento da instituição se transformam em metas imediatas, sem as quais um projeto de poder de longo prazo seria inviável. Esta autocontenção é uma precondição ou uma etapa necessária para que juízes constitucionais possam desfrutar de uma atmosfera posterior e permanente de liberdade decisória. Em circunstâncias de supremacia legislativa, a preservação da autoridade da corte é um meio para que os julgadores possam agir de maneira autônoma na afirmação de suas preferências (CLARK, 2009, pp. 972).

Após esta contextualização teórica, o próximo item explicará os critérios de seleção da jurisprudência a ser analisada pelo institucionalismo estratégico.

\section{OS CRITÉRIOS E AS FONTES DE PESQUISA}

A análise do comportamento estratégico do Supremo Tribunal no processo legislativo foi realizada através dos acórdãos decisórios da Corte, uma fonte primária de pesquisa que assume relevância ao expor a vontade institucional oficial. O acesso ao banco de julgados foi franqueado pelo endereço eletrônico oficial do Supremo, seja na página de consulta do andamento processual ou do inteiro teor dos acórdãos: www.stf.jus.br/portal/processo/pesquisarProcesso.asp e www.stf.jus.br/portal/inteiroTeor/pesquisarInteiroTeor.asp

Para que estes documentos fossem avaliados de maneira mais detalhada, apenas alguns julgados foram selecionados, seguindo o critério de importância na fixação ou inversão da jurisprudência sobre o tema.

Para mensurar esta relevância, a consulta começou pelos processos mais recentes e continuou até os mais antigos, investigando-se quais precedentes eram amplamente referenciados ao longo do tempo. Assim, foi possível constatar e selecionar quais julgados apresentaram uma envergadura jurisprudencial maior, seja por fixarem um precedente, seja por inverterem um posicionamento consolidado.

Apesar de a pesquisa ter se desenvolvido de maneira retroativa, para facilitar o entendimento, a narrativa do texto se desenvolverá de modo crescente, do caso mais antigo, em 1991, ao mais novo, em 2007. 
A seleção de julgados ficou adstrita ao momento posterior à Constituição Federal de 1988. Esta demarcação cronológica respeita a relevância que a jurisprudência política atribui ao cenário normativo-estrutural em que se desenvolvem os estudos das dinâmicas interinstitucionais. Atores individuais e organizações nunca se relacionam no vácuo, mas a partir de limites normativos que condicionam o jogo de poder no tempo. Portanto, a periodização da pesquisa não poderia escapar da quadra inaugurada na promulgação do texto constitucional vigente. Este marco temporal só foi flexibilizado uma única, vez, no estudo do Mandado de Segurança 20.257/DF, em 1980. Não havia como estudar os casos posteriores sem abordar este importante julgado que fixou um parâmetro decisório.

Como a análise se restringiu ao comportamento estratégico do Supremo em relação ao Congresso Nacional, descartaram-se os julgados sobre processo legislativo estadual e municipal.

\section{O julgamento estratégico do processo legislativo no Supremo Tribunal Federal}

O processo legislativo é regulado pela Constituição Federal e pelo Regimento Interno da Câmara dos Deputados, do Senado Federal e do Congresso Nacional ${ }^{6}$, que especificam as diferentes espécies normativas e traçam as linhas mestras de como devem ser aprovadas.

Como a criação das leis se constitui na função mais natural e típica do Congresso Nacional, a intervenção do Supremo Tribunal Federal neste processo se transforma num tema extremamente sensível nas relações interinstitucionais.

Sob a égide da Constituição de 1967, o Mandado de Segurança 20.257/DF, julgado em 8 de outubro de 1980, tratou de um projeto de emenda constitucional que prorrogava o mandato de vereadores e prefeitos de dois para quatro anos, o que, segundo os impetrantes, os senadores Itamar Franco e Antônio Mendes Canale, violaria o princípio republicano de periodicidade e não perpetuação no poder.

Esta possibilidade de intervenção na esfera legislativa mostrou divergência entre os ministros. Apesar de alguma discordância colegial, o Supremo Tribunal Federal estabeleceu um "leading case" que garantia a possibilidade de um parlamentar propor um mandado de

${ }^{6}$ Art. 59 ao art. 69 da CF; Resolução do Congresso Nacional no 1 de 1970; Resolução do Senado Federal nº 93 de 1970; Resolução da Câmara dos Deputados no 17 de 1989. 
segurança contra ato inconstitucional que violasse o processo legislativo ${ }^{7}$. No entanto, a segurança não foi concedida, pois prevaleceu o entendimento de que o princípio republicano não havia sido violado. A Corte favorecia a vontade majoritária do Congresso Nacional, mas sofisticava sua decisão para assegurar uma competência que poderia ser exercida em ocasião posterior.

Porém, em vários processos, esta interferência no nascedouro normativo esbarrou na questão prejudicial da conversão do projeto normativo em lei ${ }^{8}$ e na recusa do Supremo em interferir em questões interna corporis, baseadas na competência privativa das Casas Legislativas em interpretar seus regimentos internos ${ }^{9}$.

No Mandado de Segurança 21.754-5/RJ, julgado em 7 de outubro de 1993, os deputados federais Luiz Alfredo Salomão, Hélio Bicudo, Miguel Arraes e Aldo Rebelo questionaram ato de convocação de Sessão Extraordinária para proceder à Revisão da Constituição Federal, pois alegaram um quórum inferior ao estabelecido pelo Regimento Comum do Congresso Nacional ${ }^{10}$.

Evidenciando a posição estratégica que o jogo colegial atribui à relatoria, o ministro Marco Aurélio Mello concedeu o pedido em caráter liminar, pois não entendeu que a temática envolvia um juízo político de conveniência e oportunidade do legislador, mas sim a agressão regimental, o que ensejaria o controle judicial, a defesa da ordem jurídica e do processo legislativo contra sua substituição "por critérios que variem ao sabor das forças políticas em conflito." 11

Anos depois da decisão, o ministro Sepúlveda Pertence fez referência à ressonância deste processo e às possibilidades de retaliação legislativa: "se fizeram notórias as reações de

\footnotetext{
${ }^{7}$ O STF entendeu que o mandado de segurança seria um instrumento de defesa do direito público subjetivo do parlamentar em não participar de processo legislativo inconstitucional. MS 20.257/DF, fls. 312 e 313. No mesmo sentido, o MS 20.452-4/DF, fls. 174 a 179 e o MS 32.033/DF, processo eletrônico, p. 45.

${ }^{8}$ Quando o projeto normativo impugnado se transforma em lei durante o curso do processo judicial, o STF considera seu pedido prejudicado, pois se conhecesse o mandado de segurança, estaria lhe emprestando a função de ação direta de inconstitucionalidade, para a qual o parlamentar-impetrante seria ilegítimo, à luz do art. 103, incisos I a IX, da CF/88. MS 21.648-4/DF, julgado em 5 de maio de 1993; MS 22.442/DF, julgado em 5 de agosto de 1999. No mesmo sentido, a Súmula 266 do STF, estabelece que "Não cabe mandado de segurança contra lei em tese."

${ }^{9}$ MS 22.503-3/DF, julgado em 8 de maio de 1993; MS Ag. Reg. 21.754-5/RJ, julgado em 7 de outubro de 1993; MS 22.183-6/DF, julgado em 05 de abril de 1995; MS 24.356-2/DF, julgado em 13 de fevereiro de 2003; MS 26.062-9/DF, julgado em 10 de março de 2008.

${ }^{10}$ Tratava-se da violação do art. 28 do RICN: "Art. 28. As sessões somente serão abertas com a presença mínima de 1/6 (um sexto) da composição de cada Casa do Congresso.” MS Ag. Reg. 21.754-5/RJ, fls. 281.

${ }^{11}$ MS Ag. Reg. 21754-5/DF, fls. 289 e 299.
} 
setores dominantes da Câmara dos Deputados contra o deferimento da liminar pelo Ministro Marco Aurélio no MS 21.754"12

De fato, a Mesa do Congresso Nacional manifestou-se nos autos em tom elevado, alegando que o Poder Legislativo "não pode continuar com seus trabalhos suspensos diante da Nação estarrecida, da economia traumatizada pelas incertezas institucionais e da reputação externa do País abalada pelo conflito de dois Poderes da República."13

À exceção do ministro-relator, todos os demais ministros acolheram o recurso à liminare não conheceram do mandado de segurança. Apelando que o Supremo não mudasse sua jurisprudência interferindo em questões políticas, o ministro Francisco Rezek fez referência à história institucional da Corte e afirmou que o judiciário no Brasil já possuía competências em excesso.

Este mandado de segurança foi decidido de maneira muito célere, com um intervalo de apenas quatorze dias até seu julgamento final pelo Plenário, o que demonstra o empenho do Supremo em resolver a paralisia institucional que a liminar do ministro-relator causou ao Congresso Nacional. Diante de possíveis retaliações legislativas, a Corte preservou sua integridade institucional com extrema velocidade.

No Mandado de Segurança 22.503-3/DF, dezoito parlamentares alegaram ofensa ao processo legislativo e ao Regimento Interno da Câmara dos Deputados na votação da reforma da previdência, o Projeto de Emenda Constitucional no 33-A de 1995.

Em decisão liminar de 12 de abril de 1996, o ministro Marco Aurélio Mello mais uma vez comprovou a importância colegial da relatoria ao acolher o pedido, determinando a suspensão do trâmite do Projeto. Sozinho, mas em posição extremamente estratégica, o ministro interrompeu completamente o processo legislativo.

Tendo em vista este impasse interinstitucional, o Mandado de Segurança foi ao julgamento pelo Plenário de forma rápida, em menos de um mês após a liminar, em 8 de maio de $1996^{14}$. A maioria dos ministros rejeitou a verificação de qualquer violação regimental, por se tratar de um assunto interna corporis do legislador ${ }^{15}$. Este posicionamento se solidificou na

\footnotetext{
${ }^{12}$ Este comentário foi feito no MS Ag. Reg. 23.466-1/DF, julgado em 16 de junho de 1999, portanto, seis anos depois do MS 21.754-5/RJ, decidido liminarmente no dia 5 de outubro de 1993, e em caráter final, em 7 de outubro do mesmo ano.

${ }^{13}$ MS Ag. Reg. 21.754-5/RJ, fls. 285.

${ }^{14} \mathrm{Na}$ ordem cronológica, no ano de 1996: a distribuição do processo foi feita em 11 de abril, a liminar foi concedida no dia seguinte e o julgamento, em 05 de maio.

${ }^{15}$ No MS 22.503-3/DF, os ministros Maurício Corrêa, fls. 436, Francisco Rezek, fls. 444, Carlos Velloso, fls. 449, Octávio Gallotti, fls. 484, Sydney Sanches, fls. 486, Néri da Silveira, fls. 493-502, Moreira Alves, fls. 504 e 505 e Sepúlveda Pertence, fls. 507-514, defenderam que apenas uma suposta violação da Constituição poderia
} 
ementa do acórdão e serviu de parâmetro para embasar outros julgados posteriores à decisão ${ }^{16}$.

Voto vencido, o ministro-relator Marco Aurélio Mello permaneceu fiel ao que estabelecera na concessão da liminar ao indicar a manipulação conceitual estratégica de seus pares:

"As regras norteadoras do referido processo existem para serem respeitadas, pouco importando as consequências práticas e políticas daí decorrentes. A não se entender assim, a concluir-se que, diante de alegado quadro de abandono ao que nelas se contém, Deputados que formaram em corrente minoritária somente podem vir a se lamentar, é reconhecer a magia do rótulo interna corporis, elevando-o a dogma, transformando a maioria no soberano absoluto, passando a ter a faculdade de respeitar, ou não, o Direito objetivo, as regras disciplinadoras do processo legislativo." 17

O ministro-relator ainda tornou clara sua preocupação com a autoridade institucional do Supremo Tribunal, apelando que o Plenário fosse mais incisivo na definição da margem de competência, reação e intervenção diante das reformas constitucionais que se avizinhavam nos anos vindouros. Diante da fixação de uma posição interventiva moderada, a Corte poderia ter problemas para exercer sua jurisdição em processos semelhantes no futuro.

Embora tenha rejeitado a interferência em matéria interna corporis, o Supremo Tribunal Federal se debruçou sobre a possibilidade de conhecer o mandado de segurança para apurar a suposta violação do art. $60, \S 5^{\circ}$, da Constituição Federal ${ }^{18}$. Como um substitutivo ao Projeto de Emenda havia sido rejeitado pela Casa, os impetrantes do Mandado de Segurança condenavam que pudesse haver a votação da reforma da previdência na mesma sessão legislativa.

Para defender que o Plenário apreciasse esta violação, o ministro Celso de Mello baseou a intervenção da Corte na Constituição e na democracia, um recurso que a abordagem colegial qualificaria como uma tática de referência abstrata a valores para angariar legitimidade à sua preferência:

“A opção do legislador constituinte pela concepção democrática do Estado de Direito - onde o legislador e o Judiciário desempenham papel preponderante - não pode esgotar-se numa simples proclamação retórica. A opção pelo Estado democrático de direito há de ter

ser avaliada, rejeitando a interferência judicial em questões interpretativas regimentais, da esfera interna do Poder Legislativo.

${ }^{16}$ Neste sentido, o MS 22.494-1/DF, julgado em 19 de dezembro de 1996, em fls. 374, 394 e 439.

${ }^{17}$ MS 22.503-3/DF, fls. 411.

${ }^{18}$ Art. $60, \S 2^{\circ}$, CF. A sessão legislativa como um período anual de trabalhos parlamentares, está previsto no art. 57, caput, da CF. MS 22.503-3/DF, fls. 555. 
conseqüências efetivas no plano de nossa organização política, na esfera das relações institucionais entre os poderes da República e no âmbito da formulação de uma teoria das liberdades públicas. Em uma palavra: ninguém se sobrepõe aos princípios consagrados pela Constituição." 19

Em posição muito mais cuidadosa, cioso da inconveniência institucional de interferência da Corte no Legislativo, o ministro Sepúlveda Pertence se escorou em razões práticas e no mesmo apelo a um conceito abstrato de Constituição que o ministro Celso de Mello, porém, em sentido oposto:

"Com efeito, será rara a proposição que divida o politicante Congresso onde não haja, criada pela notável imaginação criadora dos grandes parlamentares, uma polêmica regimental que viria a ter a esta Casa. Não creio vá a este ponto o judiciarismo da nossa Constituição"20

A despeito do recurso a conceitos abstratos de Constituição que o jogo colegial considera como um mecanismo de constrangimento coletivo, o pano de fundo dos debates ministeriais sempre perpassou a definição de uma margem de ação institucional do Supremo Tribunal Federal.

Embora tenha conhecido o Mandado de Segurança para apurar a suposta violação inconstitucional do processo legislativo, a Corte assumiu as alegações da Presidência da Câmara de que a continuidade do trâmite de votação se baseava numa emenda aglutinativa de diversas propostas, que não guardava correspondência com o substitutivo rejeitado - este sim, impassível de reapresentação na mesma sessão legislativa. Sendo assim, a desaprovação anterior não viciava todo o Projeto de Emenda e a ação foi indeferida.

Nas sessões de 7 e 8 de março de 2012, o Supremo Tribunal Federal julgou a Ação Direta de Inconstitucionalidade 4.029/DF, proposta pela Associação Nacional dos Servidores do Ibama contra a Lei $n^{\circ} 11.516$ de 2007, que criou o Instituto Chico Mendes de Conservação da Biodiversidade.

A Corte reconheceu que a Constituição Federal buscou ampliar os canais democráticos de provocação da jurisdição constitucional abstrata, com a necessária superação de sua jurisprudência restritiva da legitimidade de associações nas ações diretas. No entanto, declarou sua insuficiência técnica e incapacidade institucional em apreciar a conveniência da gestão do Sistema Nacional de Meio Ambiente e, por conseguinte, da criação do Instituto.

O maior debate se concentrou no fato de a Lei $\mathrm{n}^{\circ} 11.527$ ter se originado da Medida Provisória $n^{\circ} 366$ de 1997, apreciada pelo Plenário com base em um relatório singular de 
parlamentar, de acordo com dispositivo regimental ${ }^{21}$, mas em descumprimento à exigência constitucional de análise por uma comissão mista de deputados federais e senadores ${ }^{22}$.

O ministro Ricardo Lewandowski elevou a medida provisória como um instituto contextualizado com a necessidade de celeridade decisória do mundo contemporâneo e não visualizou o dispositivo regimental como uma violação inconstitucional à atividade legislativa.

Apesar desta posição isolada, o Plenário considerou que o desrespeito frontal da Constituição Federal implicava numa circunstância de déficit na fiscalização legislativa sobre o Executivo, com aprovações de medidas provisórias sem a devida cautela de uma avaliação mais ampla, ponderada e compartilhada da comissão mista.

No entanto, a maioria ${ }^{23}$ dos ministros seguiu a reticência do ministro-relator Luiz Fux, que indicou o perigo de se reconhecer a invalidade de todas as leis derivadas da conversão de medidas provisórias que não respeitaram o comando constitucional, o que geraria consequências graves à segurança jurídica em diversas relações e situações já consolidadas ${ }^{24}$.

Sendo assim, foi adotada a tese da inconstitucionalidade. Apesar de reconhecer a irregularidade na aprovação da Lei $\mathrm{n}^{\circ} 11.527$, o Supremo modulou sua decisão para que não atingisse as normas já produzidas ou em trâmite no Congresso Nacional. Apenas as novas medidas provisórias seriam obrigadas a cumprir o crivo da comissão parlamentar mista.

Numa ótica estratégica, esta sofisticação tinha como objetivo afirmar a preferência da ala majoritária do Tribunal sem gerar maiores dificuldades à atividade legislativa que resultassem em possíveis críticas e retaliações.

No Mandado de Segurança 31.816/DF, o deputado federal Alessandro Molon questionou o ato congressual de acolher o Requerimento $\mathrm{n}^{\mathrm{o}} 12$ de 2012, que solicitava urgência na votação do Veto presidencial no 38 de 2012 ao Projeto de Lei no 2.565 de 2011, norma que estabelecia um novo sistema de distribuição dos "royalties" de exploração do petróleo entre os entes federativos.

Em decisão liminar do dia 17 de dezembro de 2012, o ministro-relator Luiz Fux lembrou que a ordem constitucional de 1967 previa a aprovação tácita do veto presidencial

\footnotetext{
${ }^{21}$ Resolução do Congresso Nacional n ${ }^{\circ} 1$ de 2002, art. $5^{\circ}$, caput e art. $6^{\circ}$, caput.

${ }^{22}$ Art. $62, \S 9^{\circ}, \mathrm{CF}$.

${ }^{23}$ Além da posição contrária do ministro Ricardo Lewandowski, o ministro Marco Aurélio Mello adotou uma posição mais radical que o colegiado, acolhendo integralmente a inconstitucionalide da Lei $\mathrm{n}^{\circ} 11.527$. ADIN 4.029/DF, processo eletrônico, pp. 58-65.

${ }^{24}$ A exigência de apreciação das MPs pela comissão mista foi inaugurada em 2001, na EC $\mathrm{n}^{\circ} 32$. ADIN 4.029/DF, processo eletrônico, pp. 27 e 35.
} 
caso não fosse apreciado pelo Congresso Nacional, o que favorecia a vontade do Executivo diante da dificuldade de organização e arregimentação de forças políticas parlamentares.

No entanto, a Constituição Federal de 1988 previu um prazo de trinta dias para a apreciação, a partir do qual todas as demais proposições seriam sobrestadas até que o veto fosse deliberado. O privilégio presidencial foi afastado, concentrando-se a decisão na esfera volitiva do legislador.

Apesar de a nova ordem motivar a "vitalidade legislativa", os parlamentares se comportavam em descompasso frontal com a Constituição, num quadro omissivo de mais de três mil vetos sem deliberação congressual.

Além de reconhecer o desrespeito pelo processo legislativo constitucional, o ministrorelator criticou a omissão do Supremo em avaliar questões políticas e concordou com diversas alegações de violação regimental, como a dispensa de uma comissão mista para análise do veto e a apreciação de requerimento ausente da ordem do dia. Este quadro de irregularidades criou um procedimento legislativo ad hoc que ofendia a segurança jurídica das minorias parlamentares, o que fundamentou ainda mais sua decisão em determinar a abstenção legislativa de deliberar sobre o Veto $\mathrm{n}^{\circ} 38$.

Este posicionamento motivou o recurso da Mesa do Congresso Nacional, discutido pelo Plenário em 27 de fevereiro de 2013. O ministro-relator Luiz Fux renovou seu posicionamento de que o "desenho institucional traçado pelo constituinte" ${ }^{25}$ tinha o objetivo de estimular a manifestação legislativa tempestiva e evitar omissões que favorecessem manobras políticas contrárias à Constituição Federale ainda reforçou que quando "não quer pagar o custo social de uma decisão, os Poderes vêm ao Judiciário e a conta fica para nós" 26 . Diante desta provocação externa, seria despropositado dizer que o Supremo realiza interferências indevidas na esfera legislativa, principalmente, com base no "mito" de não interferência em normas regimentais.

No mesmo sentido, o ministro Marco Aurélio Mello citou um artigo da imprensa para chancelar a posição da relatoria em determinar o cumprimento da ordem cronológica de apreciação dos vetos presidenciais e usou recursos colegiais apelativos para afirmar que a prática legislativa estava "rasgando a Constituição Federal", numa conduta em que "a maioria esmaga a minoria" 27 , favorecendo que o veto presidencial se consubstanciasse numa ascensão

\footnotetext{
${ }^{25} \mathrm{MS}$ MC Ag. Reg. 31.816/DF, processo eletrônico, p. 15.

${ }^{26}$ MS MC Ag. Reg. 31.816/DF, processo eletrônico, p. 25.

${ }^{27} \mathrm{MS}$ MC Ag. Reg. 31.816/DF, processo eletrônico, p. 92.
} 
do Executivo sobre o Legislativo, considerações que também perpassaram o voto do ministro Joaquim Barbosa.

No entanto, o posicionamento majoritário do Tribunal se fixou na jurisprudência de refração à análise de matéria regimental e interna corporis e no argumento pragmático de que a obrigação de uma votação cronológica de mais de três mil vetos presidenciais paralisados há treze anos no Congresso seria impossível no curto prazo, trazendo consequências deletérias ao funcionamento legislativo, prejudicando seu poder de agenda e desequilibrando sua força institucional em relação ao Executivo.

Embora não tenha desprezado a flagrante inconstitucionalidade do caso, uma decisão desta natureza traria um quadro de insegurança jurídica sobre a validade de todas as normas criadas ao longo deste tempo, aprovadas em desrespeito ao processo legislativo. Além disso, alguns ministros afirmaram que o caso não trazia um mandado de segurança protetivo de direito violado, mas se configurava num meio de controle preventivo de constitucionalidade, fato inaceitável pela jurisprudência da Corte.

O ministro Gilmar Mendes criticou duramente a desídia legislativa como indicação de "alguma doença, alguma patologia, alguma distorção" 28 e afirmou que o caso tratava de um costume constitucional contra legem, apelou à integridade institucional para que os casos sobre atividades legislativas sempre fossem submetidas ao Plenário ao invés da análise singular e preferiu indeferir a liminar, apontando a necessidade de modulação da decisão futura para que a prática parlamentar fosse sanada sem consequências deletérias ao seu funcionamento ordinário ${ }^{29}$.

Esta consideração suscitou um debate em Plenário sobre a banalização da modulação, com posicionamentos que oscilaram entre a crítica e a defesa destes instrumentos de sofisticação decisória como um imperativo de acomodação à realidade institucional. Numa abordagem estratégica, esta preocupação seria um meio de minimizar retaliações legislativas.

Porém, esta modulação prometida nem veio a ocorrer, uma vez que o Congresso Nacional derrubou o veto presidencial em votação do dia 14 de março de 2013, o que culminou com a extinção do processo por perda do objeto, em 23 de agosto de 2013.

\footnotetext{
${ }^{28}$ MS MC Ag. Reg. 31.816/DF, processo eletrônico, p. 83.

${ }^{29}$ MS MC Ag. Reg. 31.816/DF, processo eletrônico, p. 82-85 e 88. No mesmo sentido, a ministra Carmem Lúcia Antunes, preferiu indeferir a liminar para construir uma solução mais ponderada no julgamento final da ação. MS MC Ag. Reg. 31.816/DF, processo eletrônico, p. 62.
} 
No Mandado de Segurança 32.033/DF, foi discutida a constitucionalidade do Projeto de Lei $\mathrm{n}^{\mathrm{o}} 14$ de 2013, que vedava a transferência das cotas do Fundo Partidário ${ }^{30}$ e do tempo de propaganda eleitoral gratuita em rádio e televisão aos parlamentares que trocassem de legenda numa legislatura.

Embora o caso importasse na grave possibilidade de intervenção judicial no processo legislativo, o ministro-relator Gilmar Mendes abdicou da faculdade de compartilhar a responsabilidade de sua decisão com o colegiado para julgar o Mandado de Segurança de maneira solitária.

Tendo em vista que a jurisprudência analisada não apontou nenhuma hipótese de chancela do controle preventivo de constitucionalidade ${ }^{31}$, nem de interferência mais aguda no processo legislativo, a conduta do ministro-relator pode ser interpretada como uma tentativa de forçar o colegiado a mudar sua posição na matéria, uma vez que os efeitos de sua decisão perdurariam até o julgamento final do mérito pelo Plenário.

Além dessa consideração estratégica colegial, não se pode desprezar o fato de que, mesmo sabendo da posição majoritária, o ministro concedeu a liminar, o que pode comprovar a tese atitudinal de que os juízes constitucionais sempre buscam suas preferências, sem preocupações com as críticas da opinião pública ou as possíveis retaliações internas ou legislativas.

Em outra ação que o jogo colegial consideraria como um recurso estratégico disponível ao papel central da relatoria, o ministro Gilmar Mendes usou de sua prerrogativa permissiva do amicus curiae para aceitar a participação dos partidos potencialmente afetados pela legislação gestada no Congresso Nacional, o que poderia encorpar sua preferência pela declaração de inconstitucionalidade do Projeto de Lei.

Todos estes expedientes surtiram efeitos parciais, uma vez que o Plenário aceitou a manifestação das agremiações políticas em formação e sua decisão liminar suspendeu o trâmite do projeto de lei no Congresso Nacional em quase dois meses ${ }^{32}$.

\footnotetext{
${ }^{30}$ O Fundo Especial de Assistência Financeira aos Partidos Políticos receitas orçamentárias da União, multas, penalidades e doações que são distribuídas entre os partidos na forma das Leis n 9.096 de 1995 e n 9.504 de 1997.

${ }^{31}$ Embora a possibilidade de intervenção judicial tenha sido afixada como uma possibilidade na ementa do MS 20.257-2/DF - citado pelo ministro-relator Gilmar Mendes no MS MC 32.033/DF, processo eletrônico, p. 9 e no MS 32.033/DF, processo eletrônico, p. 32 - a pesquisa jurisprudencial não acusou nenhum caso em que o STF tenha realmente realizado o controle preventivo de constitucionalidade de projetos de lei.

${ }^{32}$ Os efeitos da decisão liminar duraram do dia 24 de abril de 2013 até o dia de sua rejeição, no julgamento final, em 20 de junho de 2013.
} 
Retomado o julgamento pelo Plenário, em 20 de junho de 2013, o ministro-relator iniciou o processo de votação antepondo a "polêmica instaurada nos meios de comunicação" como base para sua argumentação, o que evidencia a força que os fatores exógenos possuem na decisão da Corte, conforme destacado pela abordagem do sistema político.

Apesar dos apelos da relatoria, por decisão majoritária, a Corte conheceu o Mandado de Segurança, cassou a liminar concedida e o indeferiu. $\mathrm{O}$ fundamento comum dos ministros foi a inviabilidade de intervenção no processo legislativo, uma esfera de competência parlamentar. Os únicos votos discordantes foram do ministro Celso de Mello, do ministro Dias Toffoli e do ministro-relator Gilmar Mendes ${ }^{33}$, o que já demonstra uma corrente mais substancial de votos do que as posições isoladas do ministro Marco Aurélio nos outros mandados de segurança analisados sobre a intervenção do Supremo no processo legislativo. Em debate com o ministro Dias Toffoli, o ministro-relator Gilmar Mendes defendeu uma posição institucional mais protetiva das prerrogativas decisórias do Supremo, inclusive, contra o Poder Legislativo.

Ambos os ministros adotaram a estratégia colegial de colocar o Supremo como uma possível vítima de intervenções legislativas futuras como mecanismo de convencer seus pares a adotar sua preferência pelo controle preventivo de constitucionalidade. Embora sem surtir efeito, este recurso conota o peso que a permanência e integridade institucional podem exercer sobre a dinâmica decisória da Corte.

\section{BALANÇO}

A análise demonstrou que o Supremo Tribunal Federal reconhece sua competência interventiva no processo legislativo. Obviamente, a Corte só pode agir mediante provocação e a jurisprudência é clara em citar que apenas parlamentares teriam a legitimidade de impetrar mandado de segurança nestas situações de violação inconstitucional ${ }^{34}$.

Porém, esta restrição deve ser minorada pelo caráter agonístico da atividade legislativa, que cria um cenário habitual de disputas entre bancadas específicas e partidos. Após derrotas internas, estas forças minoritárias sempre poderão explorar o Supremo como uma esfera de apelação em ultima ratio.

\footnotetext{
${ }^{33}$ MS 32.033/DF, processo eletrônico, julgado em 20 de junho de 2013, p. 45.

${ }^{34}$ Além do precedente fixado no MS 20.257/DF, citam-se o MS 20.452-4/DF, o MS Ag. Reg. 21.303-5 /DF, o MS 27.971/DF e o MS Ag. Reg. 24.667/DF.
} 
De maneira efetiva, o processo legislativo só foi paralisado em caráter liminar, rapidamente revertida no julgamento pelo Plenário. Além destas hipóteses, somente a ADI 4.029/DF interveio com impacto relevante, ao impedir a relatoria singular das medidas provisórias em nome de uma comissão parlamentar. Apesar da limitação, esta decisão representou um afronta muito maior ao Executivo Federal, interessado na aprovação célere de seu ato, do que à competência legislativa.

Numa perspectiva atitudinal, vários ministros já demonstraram total aderência à intervenção no processo de elaboração das normas. Numa eventual alteração da formação plenarial ou diante das circunstâncias específicas de um caso, a chance de que a minoria se torne maioria é bastante grande, com a consequente aceitação ampla da tese do controle de constitucionalidade preventivo. Neste panorama, o legislador permanece sob a possível ameaça de um cenário que restrinja suas competências de forma mais incisiva.

Sob o enfoque colegial, a jurisprudência apontou a relevância de atores individuais e a estratégica posição da relatoria na interferência de assuntos da economia interna do Congresso Nacional. O "leading case" estabelecido no Mandado de Segurança 20.257/DF se configurou numa oportunidade para que alguns ministros do Supremo Tribunal Federal pudessem intervir no nascedouro da atividade típica do legislador, em decisões que paralisavam projetos contrários a suas preferências e servindo como uma alavanca de frenagem institucional à autonomia parlamentar.

Como estratégia de convencimento, o debate colegial se dividiu em torno da adoção de concepções abstratas, como o conceito de intangibilidade de questões políticas ou interna corporis - que vedam a intervenção do Supremo - ou de "Constituição" - que inspira o controle judicial sobre o Congresso Nacional. Independente do fundamento argumentativo adotado, a questão central que perpassou os julgados sempre discutiu as margens de competência da Corte, o que ficou mais evidenciado na manifestação dos ministros Marco Aurélio Mello e Celso de Mello no Mandado de Segurança 22.503-3/DF, e dos ministros Gilmar Mendes e Dias Toffolli, no Mandado de Segurança 32.033/DF, que apelaram fortemente à proteção da autoridade do Tribunal.

Uma análise institucional mais ampla poderia indicar a supremacia legislativa neste campo analítico. Este cenário seria comprovado tanto pela timidez na restrição efetiva ao labor parlamentar, quanto pelos mecanismos de sofisticação decisória, como a modulação temporal estabelecida na ADI 4.029/DF e a fundamentação em aspectos técnico-formais para a abstenção interventiva, verificada na rejeição doutrinária do controle de constitucionalidade 
preventivo e na ausência de competência para apreciar questões regimentais e interna corporis.

No entanto, uma abordagem do jogo de separação de poderes aponta num sentido diferente. Tendo em vista que a Corte goza de uma aceitação tradicional do seu papel de controle de constitucionalidade repressivo, após o processo legislativo, não precisaria se desgastar com a afirmação de sua competência para viciar a gênese normativa, o que poderia corroer seus pressupostos de legitimidade e comportamento rotinizado na cultura jurídica.

Uma interferência temerária e questionável na atividade parlamentar típica poderia despertar críticas exógenas, num cenário muito menos vantajoso que a provocação natural de atores descontentes após o aperfeiçoamento normativo, quando a atuação do Tribunal teria uma aceitação muito mais consensual. Entre o risco de enfraquecimento institucional e a maior certeza no exercício de sua competência, a Corte meramente posterga a afirmação de sua preferência ao segundo momento, quando a possibilidade de contestação decisória e evasão legislativa são muito menores.

Este seria o cerne da atuação jurisprudencial do Supremo sobre o processo legislativo: afirmar sua competência interventiva, relativizá-la com aspectos técnicos formais na conjuntura varejista de casos isolados e reservar sua atuação para um momento em que sua decisão seja menos contestada. Não troca o certo, pelo duvidoso.

\section{REFERÊNCIAS BIBLIOGRÁFICAS}

-BAUM, Lawrence. "Recruitment and Motivations of Supreme Court Justices".In: CORNELL, W. Clayton; GILlmAN, Howard. (ORG.) In: Supreme Court Decision Making: New Institutionalist Approaches. Chicago: University of Chicago Press, 1999,

-BRINKS, Daniel. "Files Servidores del Regimen. El Papel de la Corte Constitucional de Brasil bajo a la Constituición de 1988." In: Coord. FIGUEROA, Julio Ríos; HELMKE, Gretchen. Tribunales Constitucionales en América Latina. Mexico: Suprema Corte de Justicia de la Nación, 2010

-BYBBE, Keith, "Democratic Theory and Race Conscious Redistricting" In: CLAYTON, Cornell. GILLMAN, Howard. The Supreme Court in American Politics. Lawrence: University Press of Kansas, 1999 
-CLARK, Tom S. "The Separation of Powers, Court Curbing, and Judicial Legitimacy." In: American Journal of Political Science, Vol. 53, No. 4, October 2009.

-CLAYTON, Cornell. "The Supreme Court and Political Jurisprudence: New and Old Institutionalisms". In: CORNELL, W. Clayton; GILLMAN, Howard. (ORG.) Supreme Court Decision Making: New Institutionalist Approaches. Chicago: University of Chicago Press, 1999.

-CORWIN, Edward. The Twilight of the Supreme Court. New Haven: Yale University Press, 1934.

-DAVIDSON, Roger H. "What Judges Ought to Know about Congress.” In: Towards Institutional Comity. Washington D. C.: The Brooking Institute, 1988, pp. 96-102 e 110.

-DAVIS, Sue, DAVIS, Sue. "The Chief Justice and the Judicial Decision-Making: The Institutional Basis for Leadership on the Supreme Court." In: CORNELL, W. Clayton; GILLMAN, Howard. (ORG.) Supreme Court Decision Making: New Institutionalist Approaches. Chicago: University of Chicago Press, 1999.

-EPSTEIN, Lee. KNIGHT, Jack, EPSTEIN, Lee. KNIGHT, Jack. "Mapping Out the Strategic Terrain: The Informational Role of Amicus Curiae”. In: CORNELL, W. Clayton; GILLMAN, Howard. (ORG.) Supreme Court Decision Making: New Institutionalist Approaches. Chicago: University of Chicago Press, 1999.

-ESKRIDGE, William N. Jr., "Overriding Supreme Court Statutory Interpretation Decisions" (1991). In: The Yale Law Journal Vol. 101: 331.

-FEREJOHN, John A.; KRAMER, Larry. "Independent Judges, Dependent Judiciary: Institutionalizing Judicial Restraint” In: 77 N.Y.U. Law Review Rev. 962, 2002.

-HARVEY, Anna; FRIEDMAN, Barry, "Pulling Punches: Congressional Constraints on the Supreme Court's Constitutional Rulings, 1987-2000” In: Legislative Studies Quaterly, XXXI, 4, November 2006.

-HELMKE, Gretchen; STATON, Jeffrey K., HELMKE, Gretchen; STATON, Jeffrey K. "E1 Rompecabezas de la Política Judicial em América Latina: uma Teoria sobre el Litigio, las Decisiones Judiciales y los Conflitos entre Poderes.” In: FIGUEROA, Julio Ríos; HELMKE, 
Gretchen. Tribunales Constitucionales en América Latina. Mexico: Suprema Corte de Justicia de la Nación, 2010.

-MALTZMAN, Forrest; SPRIGGS II, James; WAHLBECK, Paul J. "Strategy and Judicial choice: New Institutionalist Approaches to Supreme Court Decision-Making.” In: CORNELL, W. Clayton; GILLMAN, Howard. (ORG.) Supreme Court Decision Making: New Institutionalist Approaches. Chicago: University of Chicago Press, 1999.

-ROGERS, James, "Information and Judicial Review: A Signaling Game of Legislative-Judicial Interpretation.” In: American Journal of Political Science. Vol. 45, nº 1, jan., 2001.

-SEGAL, Jeffrey; LINDQUIST, Stefanie A. "Congress, the Supreme Court, and Judicial Review: Testing a Constitutional Separation of Powers Model.” In: American Journal of Political Science, $n^{\circ} 480$, Setembro, 2010.

-__ "Supreme Court Deference to Congress: An Examination of the Marksist Model.” In: CORNELL, W. Clayton; GILLMAN, Howard. (ORG.).Supreme Court Decision Making: New Institutionalist Approaches. Chicago: University of Chicago Press, 1999

; SPAETH, Harold J. The Supreme Court and the Attitudinal Model Revisited.

New York: Cambridge University Press, 2002

. "Separation-of-Powers Games in the Positive Theory of Congress and Courts.” In: The American Political Science Review, vol. 91, nº 1, Mar., 1997.

-SPILlER, Pablo T.; RICHMAN, Barack; BERGARA, Mario. "Modeling Supreme Court Strategic Decision Making: The Congressional Constraint" In: Legislative Studies Quaterly, XXVIII, 2, May 2003.

-WEINGAST, B.; MARSHALL, W. "The Industrial Organization of Congress.” In: Journal of Political Economy, 96, 1988.

-VANBERG, Georg. "Legislative-Judicial Relations: A Game-Theoretic Approach to Constitutional Review", American Journal of Political Science, Vol. 45, No. 2, April 2001. 